\title{
Agroindústria Familiar, ODS's $e$ Desenvolvimento Alternativo: um estudo sobre a Fonte do Sabor do Semiárido Paraibano/Brasil
}

\author{
Ricélia Maria Marinho Sales \\ Universidade Federal de Campina Grande - Pombal - Paraíba - Brasil \\ Mônica Tejo Cavalcanti \\ Universidade Federal de Campina Grande - Pombal - Paraíba - Brasil \\ Karla Jarlita de Moura Silva \\ Universidade Federal de Campina Grande - Pombal - Paraíba - Brasil \\ Patrícia de Jesus Silva \\ Universidade Federal de Campina Grande - Pombal - Paraíba - Brasil
}

\begin{abstract}
Resumo
O objetivo geral foi apresentar a relação entre os Objetivos do Desenvolvimento Sustentável (ODS's), o Desenvolvimento Alternativo e a Agroindústria familiar rural de polpa de fruta Fonte de Sabor como fruto da união de mulheres agricultoras familiares do Assentamento São João II que localiza-se no espaço rural de Pombal, território do Médio Piranhas, estado da Paraíba, Brasil. A estrutura conceitual pauta-se: na organização, produção e comercialização coletiva de alimentos; na teoria do desenvolvimento alternativo; no desenvolvimento rural; na sustentabilidade; e, no Sistema de Indicadores do Desenvolvimento Alternativo e Sustentável para a Agricultura Familiar - DASAF. A metodologia seguiu a lógica analítico-descritiva e os procedimentos adotados foram: pesquisa bibliográfica, rodas de conversas com as mulheres, articuladores institucionais que são os representantes do SEBRAE, EMATER, Incubadora IACOC/UFCG e discentes do CCTA/UFCG e, aplicação das variáveis que compõem a dimensão "modo de organização" do Sistema de Indicadores DASAF. Como resultado, constatou que na agroindústria Fonte do Sabor, que conta com o acompanhamento de articuladores institucionais, há a prevalência de mulheres na produção e comercialização de alimentos, da mesma maneira que o modo de organização "associativo" prevalece em comparação com o "cooperativo" e, que os apoios institucionais se destacam tanto na orientação dos extensionistas da EMATER, incentivando o plantio sem agrotóxico de frutíferas, quanto na contribuição da aquisição de equipamentos, e também na capacitação que aborde as boas práticas de fabricação, bem como, nas orientações para adoção de práticas ambientais sustentáveis.
\end{abstract}

Palavras-chave: Sistema agroalimentar. Solidariedade. Território. 


\title{
Family Agroindustry and the SDG's: a study on the "Fonte do Sabor" of the Semi-Arid Paraibano/Brazil
}

\begin{abstract}
The general objective was to present the relationship between the Sustainable Development Goals (SDG's), Alternative Development and the rural family agro-industry of fruit pulp and which is the union of family farmer women from the Fonte de Sabor by São João II in the rural area of Pombal, in the territory of the Médio Piranhas, state of Paraíba, Brazil. The conceptual framework is based on the collective organization of women, including the production and sale of food; in alternative development theory; rural development; sustainability; and in the System of Indicators of Alternative and Sustainable Development for Family Agriculture DASAF. The methodology followed the analytical-descriptive logic and the adopted procedures were: bibliographic research, conversation with women, institutional articulators and application of the variables that compose the dimension of organization of the DASAF Indicator System. As a result, she found that among the agroindustries that are accompanied by the institutional articulators there is the prevalence of women in the production and marketing of food, just as the "association" mode of organization prevails in comparison with the "cooperative" and that the supports institutional aspects stand out in the point of view of the Agroindústria Fonte do Sabor, both in the orientation of the extension workers, encouraging the planting of fruit without pesticides, as well as in the contribution of acquisition of equipment, and also in the training that addresses good manufacturing practices, as well as in the guidelines for adopting sustainable environmental practices.
\end{abstract}

Keywords: Agrifood system. Solidarity. Territory.

\section{La agroindustria familiar y los ODS's: un estudio sobre la "Fonte do Sabor" del Semiárido de Paraíba/Brasil}

\section{Resumen}

El objetivo general fue presentar la relación entre los Objetivos de Desarrollo Sostenible (ODS's), Desarrollo Alternativo y la agroindustria familiar rural de pulpa de fruta Fonte do Sabor es la unión de mujeres agricultoras familiares del Asentamiento São João Il que se ubica en el espacio rural de Pombal, territorio del Medio Piranhas, estado de Paraíba, Brasil. La estructura conceptual se regula: en el modo de organización colectiva de las mujeres del campo que incluye la producción y la comercialización de alimentos; en la teoría del desarrollo alternativo; desarrollo rural; en la sostenibilidad; y en el Sistema de Indicadores del Desarrollo Alternativo y Sostenible para la Agricultura Familiar - DASAF. La metodología siguió la lógica analítica-descriptiva y los procedimientos adoptados fueron: investigación bibliográfica, ruedas de conversaciones con las mujeres, articuladores institucionales (SEBRAE, EMATER, Incubadora IACOC/UFCG y Discentes del CCTA/UFCG) y, aplicación de las variables que componen la variable dimensión modo de organización del sistema de indicadores DASAF. Como resultado, constató que entre las agroindustrias que son acompañadas por los articuladores institucionales hay a la prevalencia de mujeres en la producción y comercialización de alimentos, de la misma manera que el modo de organización "asociación" prevalece en comparación con la "cooperativa" y que los apoyos de acuerdo con lo establecido en la Ley Orgánica 15/1999, en el marco de la reforma agraria y la reforma agraria mientras en las orientaciones para la adopción de prácticas ambientales sostenibles.

Palabras clave: Sistema agroalimentario. Solidaridad. Territorio.

\section{Introdução}


O Brasil vivenciou até poucos anos atrás um processo de inclusão de regiões e atividades socioeconômicas tidas na informalidade e na invisibilidade das políticas públicas, fato que possibilitou a construção de estruturas de convivência com as especificidades naturais, com capacidade adaptativa que contribuiu com a minimização da vulnerabilidade socioambiental e, consequentemente auxiliando na mitigação dos riscos que resultam na "expulsão" das pessoas de suas terras.

Os arranjos produtivos presentes na região Nordeste e, especificamente nos territórios rurais presentes no semiárido brasileiro funcionaram mesmo enfrentando um dos períodos mais severos de escassez das chuvas, isto devido ao apoio institucional que fez aflorar a diversidade de atividades, de produtos, de postos de trabalho e de oportunidade de negócios oriundas de ações coletivas. Viu-se então que os projetos nacionais tiveram um diálogo direto com o local surtindo efeitos positivos, resplandecendo os casos de sucessos que são aqueles baseados em histórias reais que demonstram persistência e servem de inspiração, tal qual a agroindústria Fonte de Sabor, que podem até mesmo estar localizados em territórios desarticulados, com áreas vulneráveis pela ausência de estímulos e orientações, mas que conseguiram ultrapassar a visão dos técnicos convencionais, que tiveram a capacidade de afirmar que na terra rachada do Semiárido não haveria ambiente para gerar vida, logo seria “impossível” alcançar o desenvolvimento.

O fato, é que vivenciou-se que o "problema" nunca foi ambiental. Esta era uma afirmativa para gerar uma letargia num povo forte, que demonstra a cada dia a capacidade de atingir níveis satisfatórios de desenvolvimento com qualidade de vida, com proteção à natureza e com inclusão de todas as pessoas. E, por isso utilizou-se os constructos teóricos, quais sejam: agroindústria, território rural e desenvolvimento alternativo e sustentável, que serviram de lentes para compreender este momento da história socioeconômica do Brasil, dos territórios rurais, dos municípios e dos empreendimentos familiares (PERAFÁN, et. al., 2018).

A constatação vem a partir da observação do modo de organização da atividade da agroindústria de polpa de fruta Fonte de Sabor estruturada por agricultoras e agricultores familiares do Assentamento São João II que localiza-se no espaço rural de Pombal-PB, Estado da Paraíba, Semiárido Brasileiro. Assim, analisouse elementos que demonstram a possibilidade de vinculação entre a atividade, a teoria do desenvolvimento alternativo e a sustentabilidade (LEFF, 2010).

Nota-se que a forma de organização da agroindústria ultrapassa o modelo de desenvolvimento pautado no aspecto meramente econômico, pois a preocupação dos agricultores não é ter uma influência direta no PIB municipal, mas é ter a capacidade de motivar vidas a permanecer convivendo com as especificidades locais, sem se conformar com o sofrimento, sem esperar por paternalismos e, sim tornandose agentes de seus próprios destinos e, buscando melhor condição de vida.

Assim, é preciso considerar as formas de organização sociais de agricultores familiares, camponeses, indígenas, quilombolas, pois apesar de não se destacarem por elementos econômicos, estes muitas vezes apresentam o caminho para tornar concreto os princípios e as ações baseados na sustentabilidade, na qualidade de vida, na proteção à natureza, na possibilidade de inclusão das pessoas em atividades produtivas e, na saúde física e mental das pessoas (CARVALHO; FRANCO, 2012). 
Mediante esta realidade, Santos e Rodríguez (2002), afirmam que esta construção de uma "nova sociedade" é possível, no entanto, as pessoas precisam querer construí-la. Os autores denominam este tipo de desenvolvimento como "alternativo". A utilização do adjetivo "alternativo" apresenta-se pela falta de um termo mais adequado, mas refere-se à adoção de práticas e teorias que desafiam os modos do sistema capitalista, ou seja, seria "a conveniência política e teórica de qualificar algo que cede terreno aquilo a que se pretende opor" (SANTOS; RODRÍGUEZ, 2002, p. 27).

O desenvolvimento alternativo pauta-se na ideia de construção de formas de sociedades mais justas, cuja exploração seja eliminada, ou pelo menos drasticamente reduzida para que haja uma emancipação social. Neste sentido, esta segue os preceitos da autonomia, que um grupo de pessoas pode conseguir a partir das ações coletivas que visem um bem comum. Para tanto, um grupo precisa de modo consciente buscar "a apropriação coletiva, a descentralização e a participação no processo produtivo, na vida em sociedade e na criação cultural” (CATTANI, 2006, p. 44).

Por conseguinte, as pessoas envolvidas no processo de trabalho conseguem apresentar formas de organização econômica, segundo Santos e Rodríguez (2002) "baseadas em iniciativas coletivas, geralmente plasmadas em empresas e organizações econômicas populares de propriedade e gestão solidária que tentam contrariar, por um lado, a separação entre capital e trabalho e, por outro lado, a necessidade de recorrer à ajuda estatal" (SANTOS; RODRÍGUEZ, 2002, p. 47), uma vez que, o desenvolvimento alternativo não acredita nem numa economia centrada apenas nos meios de produção capitalista, nem num regime econômico controlado pelo Estado.

O objetivo geral deste artigo foi apresentar a relação entre os Objetivos do Desenvolvimento Sustentável (ODS's) e a agroindústria familiar rural de polpa de fruta Fonte de Sabor como fruto da união de mulheres agricultoras familiares do Assentamento São João II que localiza-se no espaço rural de Pombal, território do Médio Piranhas, estado da Paraíba, como sendo um exemplo de iniciativa do desenvolvimento alternativo e solidário no semiárido brasileiro.

O Território rural do Médio Piranhas (Figura 1) é composto por 16 municípios do Sertão da Paraíba, dentre os quais está Pombal, localizado assim, no Semiárido Nordestino. Refere-se a uma área de aproximadamente $5.156 \mathrm{Km}^{2}$, com 169.980 mil habitantes (em 2010, segundo o Censo do IBGE), dentre os quais quase $50 \%$ perfaz a população rural, o que em números absolutos trata-se de um pouco mais de 52.266 habitantes. No entanto, apenas 16.674 pessoas são ocupadas na agricultura familiar e, ocupam 6.048 estabelecimentos. No tocante a quantidade de área apropriada pelo processo da Reforma Agrária tem-se aproximadamente 15.404 hectares. 
Figura 1. Mapa de localização do Território Rural do Médio Piranhas

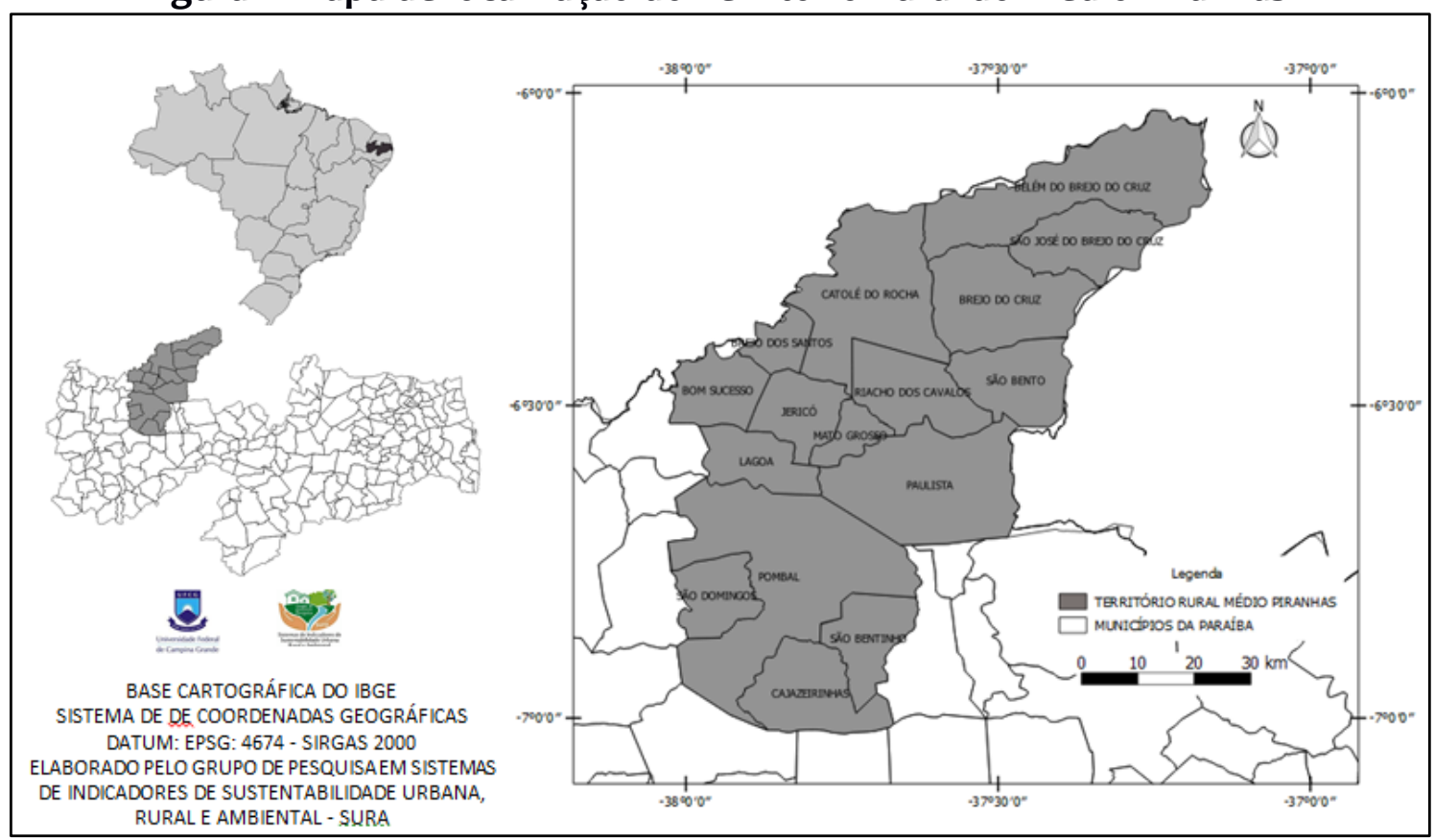

Fonte: Elaborado por LabGeo/CCTA/UFCG e por membros do Grupo de Pesquisa SURA/UFCG/CNPq, 2018.

Por estar inserido na região Nordeste, o município encontra-se em uma área tida nacionalmente e internacionalmente como atrasada, como região problema e, fatalmente pouco desenvolvida a partir da interpretação do conceito clássico de desenvolvimento (FURTADO, 1983; FURTADO, 2002; OLIVEIRA, 1981; SUDENE, 1994). Somam-se, ainda as especificidades de fatores climáticos, que marcam os períodos irregulares de chuvas.

As características naturais peculiares demonstram resistência e potencial de resiliência na mesma proporção que revelam a necessidade de adequação políticoinstitucional para lidar com as fragilidades ambientais, o incentivo à inovação e adoção da tecnologia social para criar infraestruturas adequadas de convivência e, consequentemente para harmonizar a qualidade de vida das pessoas às atividades socioeconômicas. Nesse sentido, a agricultura familiar pode vir a ser um elemento fundamental para fortalecer a abordagem territorial do desenvolvimento que equilibra as esferas sociais, econômicas, ambientais e político-institucionais.

\section{A abordagem territorial como uma escala para as Agroindústrias concatenar o desenvolvimento alternativo e os Objetivos do Desenvolvimento Sustentável (ODS's)}

A abordagem territorial do desenvolvimento, no Brasil, caminhou lado a lado com os Objetivos do Desenvolvimento do Milênio (ODM) da Organização das Nações Unidas (ONU) que tinha o foco em promover o desenvolvimento social nos países signatários. De modo específico pode-se destacar no Brasil o Plano Brasil Sem Miséria (2011-2015), que pode ser entendido como um programa guarda-chuva com impactos nacionais e inspirando ações internacionais, cujo foco foi a superação da pobreza a 
partir do aumento da capacidade e da geração de oportunidade para as pessoas socialmente mais vulneráveis (MELLO, 2018).

A relação entre o Plano Brasil Sem Miséria e a política territorial de desenvolvimento rural foi direta. O ponto de intercessão mais marcante foi colocar em prática a abordagem territorial como elemento fundamental para o planejamento e gestão de políticas públicas em 22 ministérios, incluindo o Ministério do Desenvolvimento Agrário, visando combater as desigualdades e promover justiça social, o que possibilitou fortalecer as relações familiares e comunitárias entre pessoas em situação de vulnerabilidade social e ambiental no campo e na cidade.

No ano de 2014, o Brasil foi reconhecido pela Organização das Nações Unidas para a Alimentação e Agricultura (FAO) como um país que erradicou a fome, simplesmente por ter tomado a decisão política de promover o crescimento econômico com a distribuição de renda, fato que possibilitou alcançar a redução das desigualdades e da pobreza (FAO, 2016). Mas para tanto foi necessário a efetivação de algumas políticas públicas para refinar a sintonia entre as dimensões econômicas, sociais e ambientais.

Dentre as políticas públicas propostas a época destacam-se aquelas que apresentaram a capacidade de abrir diálogos comuns entre ministérios, tais quais: 0 Ministério do Desenvolvimento Agrário (MDA), Ministério do Desenvolvimento Social (MDS), Ministério da Agricultura, Pecuária e Abastecimento (MAPA), Ministério do Meio Ambiente (MMA); visando integrar as ações emergenciais garantindo a segurança alimentar e nutricional com àquelas que possibilitaram o acesso das comunidades rurais a direitos fundamentais e serviços públicos, promovendo um embrião mesclado de justiça, de inclusão social e de desenvolvimento sustentável.

As políticas públicas geradas à época foram capazes de estruturar programas, tais quais: Arca das Letras; Programa Nacional de Alimentação Escolar (PNAE); Selo de Identificação da Participação da Agricultura Familiar (SIPAF); Programa de Cadastro de Terras e Regularização Fundiária (PCTRF); Programa de Aquisição de Alimentos (PAA); Garantia Safra; dentre outros que em maioria foram extintos nos dias atuais.

$\mathrm{Na}$ oportunidade destaca-se que o passado recente firmou-se como um momento essencial para descortinar a riqueza revelada pela diversidade nas formas de fazer a agricultura familiar, as particularidades dos modos de vida das comunidades, a qualidade do alimento que assegura a nutrição e a proteção à natureza, do despertar de uma consciência de que para o Brasil pode ser mais promissor o abandono do setorialismo e a adoção da territorialização de pessoas, de objetos, de ações, de fixos e fluxos (HAESBAERT, 1999; SANTOS, 2010). Assim, colocou-se em prática os territórios rurais como unidades de planejamento e de gestão pública, adotando políticas contextualizadas e focadas na organização social territorial através do Programa de Desenvolvimento Sustentável dos Territórios Rurais (PRONAT).

A ideia central do PRONAT foi proporcionar o aumento da capacidade produtiva, a geração de empregos e a melhoria da renda criando oportunidades para que as populações rurais alcançassem a plena cidadania e assim fossem incluídas no desenvolvimento. Este foi um elemento essencial para possibilitar a estruturação dos empreendimentos da agricultura familiar. Deste modo, o governo federal ratificou 
que esta seria uma estratégia para superação da pobreza e da promoção da geração de renda como mecanismo para alcançar o desenvolvimento sustentável (SANTOS, et. al, 2014).

O ano de 2015 foi o marco inicial dos Objetivos do Desenvolvimento Sustentável (ODS's) que fazem parte da Agenda 2030 e foram construídos de modo participativo por representantes governamentais e da sociedade civil de 163 países. $\mathrm{Na}$ oportunidade, o Brasil assinou o protocolo e tornou-se signatário, comprometendo-se em atingir as metas oriundas dos indicadores socioeconômicos com vistas à promoção de um modelo de desenvolvimento sustentável. Não obstante, trata-se então de uma agenda mundial firmada em quatro temas referentes à cidadania, meio ambiente, economia e relações institucionais.

Apesar de ter sido uma decisão política representativa, a Agenda 2030 é algo para ser apropriado por cada cidadão no seu exercício individual e coletivo, fato que não diminui as responsabilidades de quem está representando e ocupando os espaços de decisões administrativos em escala municipal, territorial, estadual, nacional e global, visto que esta agenda é um plano de ação para as pessoas e também para planeta apresentando uma visão individual e também global para alcançar a prosperidade. Por conseguinte, requer compromisso, transparência das sociedades e suas institucionalidades, visando acionar os mecanismos para manter seus representantes como entes responsáveis por suas obrigações assumidas em convenções internacionais (ENGEBRETSEN; HEGGEN; OTTERSEN, 2017).

Assim, há a necessidade de clarividência do setor público sobre os problemas sociopolíticos que estão vinculados, tanto aos modelos prioritários que geraram distorções regionais e territoriais (OLIVEIRA, 2011), quanto à subserviência aos modelos hegemônicos de desenvolvimento que andam na contramão do que preconiza o desenvolvimento sustentável (RIELLA, 2006).

Deste modo, a participação, a sensibilização e criação de espaços de diálogos sobre os ODS's precisam ser estimulados para que cada pessoa tenha o poder de disseminar e de exercer seu papel de articulador mediante as possibilidades de retirar do papel as ações e estratégias apresentadas no sentido de garantir a defesa, a democratização e a localização da Agenda 2030.

A agenda 2030 pode proporcionar a facilitação do diálogo entre diferentes atores sociais e setores visando à estruturação de processos de tomada de decisão e, elaboração consistente de políticas públicas que atendam às necessidades reais e os pontos de convergência visando atingir objetivos comuns. Assim, compreende-se que a definição e adequação dos indicadores pode ser visualizado tanto como um elemento que facilita a identificação de problemas e de avanços, quanto no alcance de objetivos e metas estabelecidos para promover o desenvolvimento sustentável.

Os temas destacados nos ODS's podem proporcionar a formação de redes multiescalares e multissetoriais, a construção de plataformas de conhecimento e de troca de informações e saberes, ampliando a compreensão de processos e edificando novas formas de pensamento, motivando a criação de ferramentas, de metodologias, de instrumentos de gestão e de inovação de processos, produtos e serviços, ou seja, abre-se a possibilidade de colocar em prática as novas maneiras de pensar em produção e em distribuição, como conseguiu descrever Yunus (2008).

Por outro lado, a abordagem territorial do PRONAT possibilita 0 fortalecimento dos sistemas agroalimentares no tocante a organização, a efetivação 
das redes de agricultoras e agricultores que colocam em prática a economia solidária, que compartilham saberes e sabores. Estas pessoas que constituem as redes estão abertas às inovações sociotécnicas, a gestão social, aos mecanismos de governança territorial e ao enfrentamento aos conflitos socioambientais, até porque o território rural, em sua essência, tem o poder de apontar, mobilizar, reconhecer e propor soluções para seus problemas específicos.

Nos últimos anos estes programas foram abortados e desestruturados em escala nacional, mas mesmo assim, em algumas localidades do país, ainda é possível identificar a resistência de territórios rurais que tiveram maturidade suficiente para permanecer vivos e ativos na sua organização, mobilizando atores sociais em escalas estaduais. Outros estão adormecidos, mas ainda contam com estruturas pontuais que foram resultado deste momento relevante de organização, como é o caso do Território Rural do Médio Piranhas e dos empreendimentos produtivos coletivos de agricultoras e agricultores familiares, atingindo o objetivo de redução da pobreza e da geração de renda, a ponto de mudar a realidade das pessoas e promover qualidade de vida em equilíbrio com a natureza.

Na atualidade ainda é possível verificar como se deu esta transformação social resultando na promoção da sustentabilidade social, econômica e ambiental, tal qual é o caso específico da agroindústria Fonte do Sabor. Este empreendimento pode ser entendido como o resultado do acesso, do assessoramento e dos espaços de participação que foram frutos da Política Territorial Brasileira. Esta política pública foi além da infraestrutura física, dos programas de cisternas de produção e de dessedentação humana também ofereceu a oportunidade de formação e qualificação com programas, planos e projetos de vinculação direta executada pelo Ministério do Desenvolvimento Agrário (MDA) ou por vinculação indireta executada por outros ministérios e órgãos, mas que chegaram até o campo e ao interior das regiões brasileiras, cumprindo exatamente o que preconizam os Objetivos do Desenvolvimento Sustentável.

As informações históricas e do dia a dia das pessoas que moram e trabalham no assentamento São João II apresentam um empreendimento produtivo como exemplo de sucesso e, ainda demonstra que a relação entre terra-trabalho-moradia vem passando por gerações. As famílias se tornaram donas da terra por meio de um projeto financiado governamental, processo que teve sua origem a partir da Propriedade São João pertencente a Hamlet de Assis Arnaud. Após o falecimento do proprietário a terra ficou de herança para as filhas que residiam na Capital do Estado da Paraíba, João Pessoa, que dista a 372 km de Pombal. A distância foi um dos motivos pelo quais as mesmas resolveram vender a fazenda através do Programa do Governo Federal Banco da Terra, assumindo assim a categoria de Assentamento.

No ano de 2001 houve a aquisição desta terra por parte dos agricultores familiares através do financiamento oferecido pelo Banco da Terra, cujas parcelas não levaram em consideração as condições de pagamento dessas pessoas, fato que gerou uma dívida. No entanto, no ano de 2003 com o advindo do Crédito Fundiário, a dívida foi renegociada com o governo federal e, os assentados conseguiram honrar com sua dívida e, sanar o pagamento das parcelas que faltavam. Estes já tinham relação com a terra, uma vez que seus descendentes eram meeiros. $O$ assentamento São João II foi criado e, a propriedade foi parcelada em quinze lotes de dezessete hectares. Assim, os próprios moradores da fazenda assumiram o papel de 
assentados, deixando a condição de parceiros para transformarem-se em proprietários, conquistando a posse da terra.

A agroindústria Fonte de Sabor, localizada no assentamento São João II, foi construída a partir do acesso ao crédito disponível no Programa de Redução a Pobreza Rural (PRPR) que foi fruto da ação do Governo do Estado da Paraíba (20062014), com a permissão do governo federal (porque o financiamento da terra ainda não tinha sido concluído). As agricultoras foram em busca por empréstimo junto ao Banco Internacional para Reconstrução e Desenvolvimento (BIRD), que segundo Souza (2015), teve o objetivo estratégico de promover "a descentralização, participação comunitária, transparência, legitimidade das demandas e sustentabilidade dos investimentos conquistados pelos beneficiários, com foco na população pobre rural, grupos indígenas, quilombolas, mulheres e jovens" (SOUZA, 2015, p.63).

Compreende-se que as agroindústrias familiares são elos relevantes na promoção de reconexão entre produção e consumo de alimentos saudáveis e sustentáveis. Tratam-se de estratégias de agregação de valor aos produtos que em alguns casos corriam o risco de ser desperdiçados porque não havia o aproveitamento e acondicionamento para possibilitar uma comercialização segura em mercados locais ou regionais, fazendo que fossem criados novos circuitos de comercialização ou mesmo o encurtamento do elo produtor-consumidor (SCHNEIDER; FERRARI, 2015). Esta ação consegue conectar diferentes metas dos ODS's (ver Quadro 1), o que demonstra o potencial da agricultura familiar em impulsionar as estratégias descritas na Agenda 2030.

Chama-se a atenção para a matéria-prima e para o controle de todas as etapas da cadeia produtiva, elementos que possibilitam que as agricultoras e os agricultores tenham maior autonomia, distribuição igualitária do lucro e a obtenção de maiores valores agregados, fato que ocorre na Fonte de Sabor, mas que pode ser replicado em outras agroindústrias familiares rurais.

Por isso destaca-se também, que além do poder de decisão sobre os modos de cultivos, esses elementos apropriados pelas agricultoras e agricultores da Fonte de Sabor revelam os princípios de solidariedade, de igualdade e de proteção à natureza. E, esses são fatores fundamentais para o alcance dos meios de implementação dos Objetivos de Desenvolvimento da Agenda 2030, haja vista a reiteração de que as agroindústrias familiares rurais têm a capacidade de ligar as pessoas ao processo de prosperidade, como demonstra o Quadro 1: 


\section{Quadro 1. Descrição dos ODS's e Metas com contribuição direta das Ações} das Agroindústrias Familiares

\begin{tabular}{|c|c|c|}
\hline \multicolumn{3}{|c|}{ 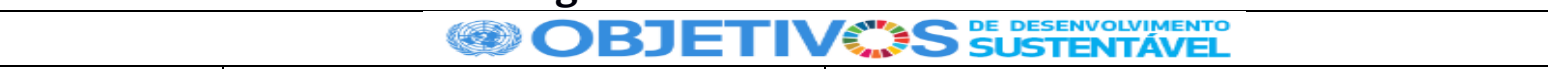 } \\
\hline Identificação & Descrição & Meta e Meios de Implementação \\
\hline ODS 2 & $\begin{array}{l}\text { Acabar com a fome, alcançar a segurança } \\
\text { alimentar e melhoria da nutrição e } \\
\text { promover a agricultura sustentável }\end{array}$ & $\begin{array}{l}\text { 2.3 - Até } 2030 \text {, dobrar a produtividade agrícola e a } \\
\text { renda dos pequenos produtores de alimentos, } \\
\text { particularmente das mulheres, povos indígenas, } \\
\text { agricultores familiares, pastores e pescadores, } \\
\text { inclusive por meio de acesso seguro e igual à terra, } \\
\text { outros recursos produtivos e insumos, } \\
\text { conhecimento, serviços financeiros, mercados e } \\
\text { oportunidades de agregação de valor e de emprego } \\
\text { não agrícola }\end{array}$ \\
\hline ODS 7 & $\begin{array}{l}\text { Assegurar o acesso confiável, sustentável, } \\
\text { moderno e a preço acessível à energia para } \\
\text { todas e todos }\end{array}$ & $\begin{array}{l}\text { 7.b Até 2030, expandir a infraestrutura e modernizar } \\
\text { a tecnologia para o fornecimento de serviços de } \\
\text { energia modernos e sustentáveis para todos nos } \\
\text { países em desenvolvimento }\end{array}$ \\
\hline ODS 10 & $\begin{array}{l}\text { Reduzir a desigualdade dentro dos países e } \\
\text { entre eles }\end{array}$ & $\begin{array}{l}\text { 10.2 Até 2030, empoderar e promover a inclusão } \\
\text { social, econômica e política de todos, } \\
\text { independentemente da idade, gênero, deficiência, } \\
\text { raça, etnia, origem, religião, condição econômica ou } \\
\text { outra }\end{array}$ \\
\hline ODS 11 & $\begin{array}{l}\text { Tornar as cidades e os assentamentos } \\
\text { humanos inclusivos, seguros, resilientes e } \\
\text { sustentáveis }\end{array}$ & $\begin{array}{l}\text { 11.a Apoiar relações econômicas, sociais e ambientais } \\
\text { positivas entre áreas urbanas, periurbanas e rurais, } \\
\text { reforçando o planejamento nacional e regional de } \\
\text { desenvolvimento }\end{array}$ \\
\hline ODS 12 & $\begin{array}{l}\text { Assegurar padrões de produção e de } \\
\text { consumo sustentáveis }\end{array}$ & $\begin{array}{l}\text { 12.7 Promover práticas de compras públicas } \\
\text { sustentáveis, de acordo com as políticas e prioridades } \\
\text { nacionais; } 12.8 \text { Até } 2030 \text {, garantir que as pessoas, em } \\
\text { todos os lugares, tenham informação relevante e } \\
\text { conscientização para o desenvolvimento sustentável } \\
\text { e estilos de vida em harmonia com a natureza; }\end{array}$ \\
\hline ODS 17 & $\begin{array}{l}\text { Fortalecer os meios de implementação e } \\
\text { revitalizar a parceria global para o } \\
\text { desenvolvimento sustentável }\end{array}$ & $\begin{array}{l}\text { 17.8 Operacionalizar plenamente o Banco de } \\
\text { Tecnologia e o mecanismo de capacitação em ciência, } \\
\text { tecnologia e inovação para os países menos } \\
\text { desenvolvidos até 2017, e aumentar o uso de } \\
\text { tecnologias de capacitação, em particular das } \\
\text { tecnologias de informação e comunicação; } \\
\text { 17.14 Aumentar a coerência das políticas para o } \\
\text { desenvolvimento sustentável }\end{array}$ \\
\hline
\end{tabular}

Fonte: ONU - Brasil; PNUD, 2018.

\section{Metodologia}

A metodologia seguiu a lógica analítico-descritiva e os procedimentos adotados foram os seguintes:

a) Pesquisa bibliográfica: esta etapa foi realizada através da consulta a produção bibliográfica da Rede Brasileira de Pesquisadores em Gestão e Desenvolvimento Territorial (RETE); em biblioteca da Universidade Federal de Campina Grande e, a Plataforma on-line dos Periódicos CAPES.

b) Rodas de conversas com as 04 mulheres pioneiras da Agroindústria, articuladores institucionais (EMATER, Incubadora IACOC/UFCG) e do Comitê de Energias Renováveis do Semiárido (CERSA). As rodas de conversas aconteceram de modo separado e, nestes momentos foi possível estabelecer pesos aos indicadores (Tabela 1) e, o grau de importância para o funcionamento do empreendimento da agricultura familiar. 
c) Aplicação do sistema de indicadores do Desenvolvimento Alternativo e Sustentável da Agricultura Familiar (DASAF). Esse foi construído por Sales (2014), de modo singular para evidenciar que as teorias do desenvolvimento alternativo e do desenvolvimento sustentável destacando a capacidade de revelar valores, práticas e costumes essenciais para maior sustentabilidade da agricultura familiar no Nordeste Brasileiro. Esta propositura sugeriu a necessidade da utilização de formas diferenciadas para analisar o processo de geração do desenvolvimento em escopos geográficos com características específicas, relacionadas a pequenas comunidades rurais. Em termos metodológicos, o DASAF iniciou-se com a realização de uma pesquisa descritiva de natureza qualitativa que possibilitou a estruturação de um sistema de indicadores para ser aplicado em unidades e/ou em comunidades rurais que apresentem características similares à agricultura familiar, no tocante à forma de organização, à viabilidade e ao potencial emancipatório.

Neste caso específico, foi realizada a aplicação apenas das variáveis que compõem a dimensão "modo de organização" do Sistema de Indicadores DASAF. Houve a adaptação e a seleção dos indicadores para focar na agroindústria que resultou na seguinte estrutura de sistema:

\section{Tabela 1. Sistema DASAF com seus princípios, temas e indicadores voltados para a} análise da Dimensão Formas de Organização para Empreendimentos da Agricultura Familiar

\begin{tabular}{|c|c|c|}
\hline PRINCÍPIOS & TEMAS & INDICADORES \\
\hline \multirow{5}{*}{ Igualdade } & Estrutura do empreendimento & Aspectos estruturais da Agroindústria \\
\hline & Trabalho & Planejamento do trabalho \\
\hline & Organização Social & Atividades sociais, políticas e culturais \\
\hline & Política Pública & $\begin{array}{l}\text { Influência de políticas públicas assistencialista } \\
\text { na unidade produtiva }\end{array}$ \\
\hline & Infraestrutura & Transporte \\
\hline \multirow{3}{*}{ Solidariedade } & $\begin{array}{c}\text { Estrutura do empreendimento } \\
\text { Trabalho }\end{array}$ & $\begin{array}{l}\text { Relações sociais no empreendimento } \\
\text { Organização do trabalho e na produção } \\
\text { Atividades empresariais }\end{array}$ \\
\hline & Organização Social & $\begin{array}{l}\text { Formação de grupos } \\
\text { Atividades de integração }\end{array}$ \\
\hline & Política Pública & $\begin{array}{l}\text { Recursos humanos e aspectos das políticas } \\
\text { públicas setoriais }\end{array}$ \\
\hline \multirow{8}{*}{$\begin{array}{l}\text { Proteção à } \\
\text { Natureza }\end{array}$} & \multirow{4}{*}{ Ambiente Natural } & Aspectos físicos/naturais da terra \\
\hline & & Cuidados com a terra \\
\hline & & Gestão ambiental e sanitária \\
\hline & & Educação Ambiental \\
\hline & Organização Social & Lazer \\
\hline & Trabalho & $\begin{array}{l}\text { Agregação de valor a produtos da agricultura } \\
\text { familiar }\end{array}$ \\
\hline & Estrutura do empreendimento & $\begin{array}{c}\text { Maximização da mercadorização - consumismo } \\
\text { e cultura de massa }\end{array}$ \\
\hline & Infraestrutura & Armazenamento de produtos \\
\hline
\end{tabular}

Fonte: Sales, 2014 .

Utilização do sistema de indicadores DASAF para a Agroindústria Fonte do Sabor, fundamentados em alguns cálculos, a saber: o cálculo da importância das variáveis que compõem o sistema DASAF, no qual estabeleceu-se a hierarquização das mesmas através da atribuição do grau de prioridade do indicador, onde o grau de 
importância 1 foi atribuído quando o indicador foi considerado Pouco Importante; 2 quando o indicador foi considerado Importante; e 3 quando o indicador foi considerado Muito Importante, sempre em relação a outro indicador com o qual está sendo comparado. Lembrando que o grau de importância foi dado pelos atores sociais a partir das Rodas de Conversa;

- O cálculo da Média de pontos por Temas, a exemplo da equação 1:

onde,

$$
\mathrm{M}_{\mathrm{n}}=\frac{\sum_{\mathrm{n} i}}{\mathrm{n}} \text { Equação (1) }
$$

$\mathrm{M}_{\mathrm{n}}=$ Média de pontos por Temas de cada Princípio

$\sum x i=$ Somatória dos Graus de importância estabelecidos pelos atores sociais para cada tema;

$\mathrm{n}$ = Número total de rodas de conversa realizadas

- O cálculo do Peso por Tema, a exemplo da equação 2:

onde,

$$
\mathrm{PT}=\frac{\mathrm{Mn}}{\sum_{\mathrm{Mn}}} \text { Equação (2) }
$$

PT = Peso por Tema

$M_{n}=$ Média de pontos por Temas de cada Princípio

$\sum_{\mathrm{Mn}}=$ Somatória das Médias dos temas de cada dimensão

- O cálculo da Média de pontos por dimensão, a exemplo da equação 3:

onde,

$$
\mathrm{M}_{\text {PтD }}=\frac{\sum_{\mathrm{Mn}}}{\mathrm{n}_{\mathrm{M}}} \text { Equação (3) }
$$

$M_{\text {PTD }}=$ Média de pontos por Princípios.

$\sum M n=$ Somatória das Médias dos temas de cada dimensão.

$\mathrm{N}_{\mathrm{M}}$ = Número total de Médias dos temas para cada dimensão.

- E, o cálculo do peso de cada Princípio vinculado ao sistema de indicadores DASAF, a exemplo da equação 4:

onde,

$$
\mathrm{PD}=\frac{\mathrm{M}_{\text {PтD }}}{\sum_{\text {MPтD }}} \text { Equação (4) }
$$

$\mathrm{PD}=$ Peso de cada Princípio

MPTD $=$ Média de pontos por Princípios .

$\sum M_{P T D}=$ Somatória das Médias de pontos por princípios.

Com isto foi possível obter os resultados explanados no item seguinte.

\section{Resultados}

A agroindústria Fonte de Sabor tem a missão de produzir e fornecer polpas de frutas com alto padrão de qualidade, além da melhoria da renda familiar dos associados da Associação Comunitária dos Agropecuaristas do São João fomentada pela comercialização solidária das mesmas.

Ainda durante o processo de integração dos proprietários houve a criação da Associação Comunitária dos Agropecuaristas do São João. O objetivo da associação foi prestar serviços que pudessem contribuir para o fomento da agricultura familiar e a defesa das atividades econômicas, sociais e culturais (prezando por manter a história dos Quilombolas) de seus associados. No início, era um grupo de quatro 
mulheres que tinha no bolso apenas $\mathrm{R} \$ 25,00$ para iniciar a atividade e que contava com o auxílio da carona do carro que distribuía leite no assentamento todas as manhãs. Elas visitavam as casas da cidade para oferecer o produto, como verbalizou a presidente da Associação:

\begin{abstract}
passamos por muitas dificuldades, mas nunca pensamos em desistir. Ao longo do caminho mostramos aos demais associados à importância do negócio para o assentamento. Hoje temos, além das mulheres, filhos e esposos envolvidos no projeto. Essa socialização de tarefas veio reduzir os nossos dilemas sociais, tornando mais fácil o desenvolvimento do trabalho em ação coletiva em outras áreas do assentamento (Presidente da Agroindústria, 2018).
\end{abstract}

Hoje, a economia do assentamento apresenta duas vertentes. Uma ligada à subsistência dos agricultores e, a outra que é voltada à comercialização de excedentes. A agricultura de subsistência é formada pelo plantio de milho, feijão e tubérculos. E, para a comercialização, os assentados criam animais (bovinos, ovinos, caprinos e, aves), produzem banana irrigada, que é escoada na forma in natura, e, também algumas frutíferas como: acerola, goiaba, manga e caju, que são beneficiadas na agroindústria de polpa de frutas (SILVA, 2008).

As polpas de fruta são produzidas dentro do assentamento, onde foi criada uma associação e através do convênio pelo Programa de Combate à Pobreza Rural (PCPR) do Projeto Cooperar do Governo Estadual instalou-se uma agroindústria denominada como Fonte de Sabor. Em épocas de escassez e/ou redução de precipitações a produção e, comercialização da polpa de fruta passa a ser a principal alternativa de sobrevivência das famílias, mas suas ações estão integradas e acompanhadas por órgãos e instituições empenhadas no desenvolvimento do meio rural.

Salienta-se que existe apoio institucional junto às atividades desenvolvidas no assentamento São João II. A assistência técnica no assentamento é realizada pela Empresa de Assistência Técnica e Extensão Rural (EMATER-PB). E, existem projetos específicos desenvolvidos pelo Instituto de Terras e Planejamentos do Estado da Paraíba (INTERPA), pela Universidade Federal de Campina Grande (IACOC/PEASA e, docentes e discentes da UFCG - (âmpus Pombal), pelo Serviço Brasileiro de Apoio às Micro e Pequenas Empresas (SEBRAE), pelo Banco do Nordeste, pela Ação do Semiárido - ASA Brasil na construção e capacitação proveniente do Programa 1 Milhão de Cisternas, pelo Sindicato dos Trabalhadores e Trabalhadoras Rural de Pombal (STTR), pelo Projeto Cooperar do Governo do Estado/PB, pela Prefeitura Municipal de Pombal através da Secretaria de Ação Social, pela ONG ESSOR, através da Association de Solidarité Internacionale cujo objetivo foi promover o treinamento de formadores para o empreendedorismo social e, pelo Comitê de Energias Renováveis do Semiárido - CERSA enquanto organizador de fóruns e articulador de parceiros, tal qual o projeto SEMIÁRIDO SOLAR financiado pelo MISERIOR que conseguiu implantar a produção de energia solar no modelo descentralizado e de microgeração.

Este é um elemento fundamental para que o ODS 7 seja cumprido e, mais que isto, para que as pessoas passem a compreender que a infraestrutura e modernização da energia aconteça, que toda unidade produtiva possa ser um ponto 
de geração de energia e não apenas mais um consumidor de concessionárias e subsidiárias. Isso gera autonomia e gestão energética ao passo que contribui para a sustentabilidade planetária.

A comercialização dos produtos da agroindústria está sendo viabilizada pelo Programa Nacional de Alimentação Escolar (PNAE), para o Programa Compra Direta da Agricultura Familiar. Com este fornecimento vinculado aos programas do governo federal em parceria com os municípios fica garantido para cada associado uma cota anual de $\mathrm{R} \$$ 4.500,00 (quatro mil e quinhentos reais). Assim, atende-se ao chamamento do ODS 2, na meta 2.3 que demonstra a importância de práticas que aumentam a renda dos pequenos produtores de alimentos, particularmente das mulheres. Acrescentam-se outros tipos de comercialização e, atinge-se uma média de renda mensal por associado de $\mathrm{R} \$ \mathbf{7 0 0 , 0 0}$ (setecentos reais). Mas, a divisão do lucro só ocorre após o pagamento das despesas, daí divide-se por todos de forma igualitária.

A agroindústria Fonte de Sabor processa os seguintes frutos: uva, goiaba, manga, acerola, caju, cajá, graviola, maracujá, mamão com acerola, abacaxi com hortelã (Figura 1). E, através da constituição do Fórum Sertanejo de Economia Solidária que articula através do Programa de Ações Sociais de Políticas Públicas (PASPP) da Igreja Católica, Diocese de Cajazeiras/PB ocorre a troca solidária entre produtos in natura e/ou produtos beneficiados. A partir desta prática a agroindústria passou a receber Umbu oriundo da região de Teixeira, Território da Cidadania do Médio Sertão e, em troca repassam Acerola cujo fruto há em abundância no Território Rural do Médio Piranhas. A participação em fóruns e outros tipos de coletivos são relevantes para o ODS 12 que visa a garantia que as pessoas tenham informações de qualidade e conscientização para o desenvolvimento sustentável e que o estilo de vida esteja em harmonia com a natureza.

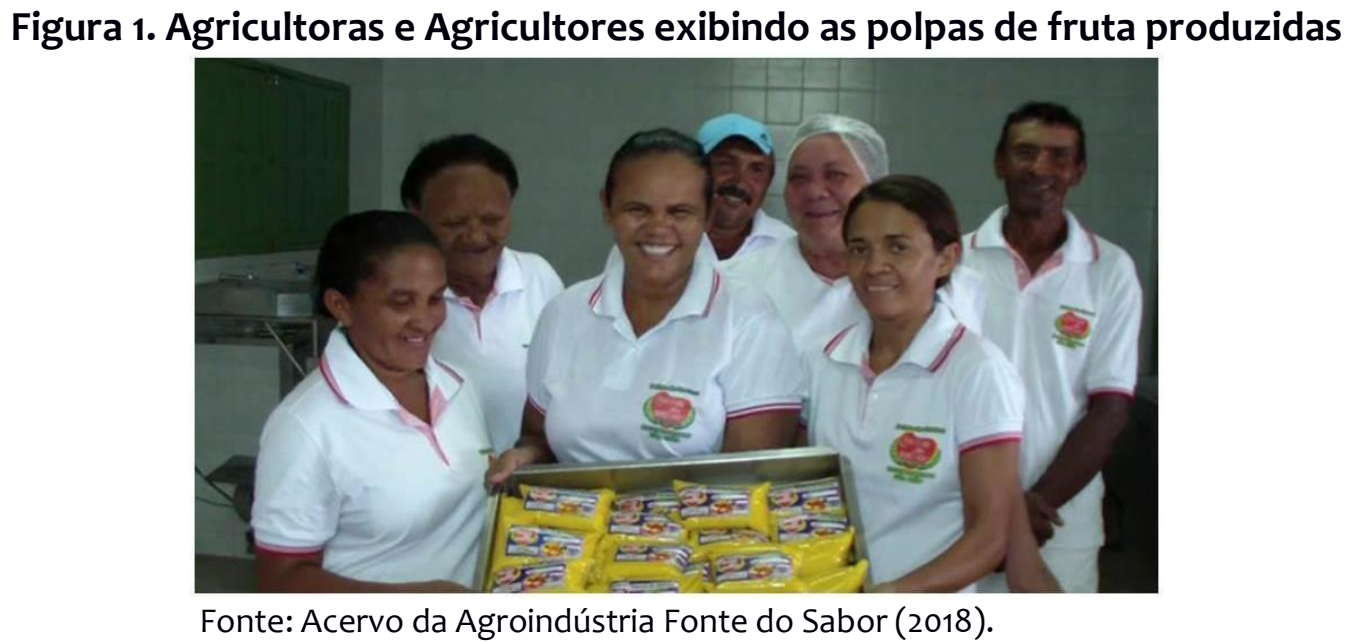

O processamento de polpa de frutas congelada inclui uma sequência de etapas que deve ser seguida a fim de se obterem produtos dentro dos padrões de segurança do alimento estabelecidos pelo Ministério da Saúde (MS) e Ministério da Agricultura, Pecuária e Abastecimento (MAPA). A comercialização para os supermercados, lanchonetes e comércio em geral será realizada após aquisição do 
Serviço de Inspeção Federal (SIF), que se encontra em processo de liberação junto ao MAPA.

As atividades de aquisição de matéria-prima, de processamento e de comercialização apontam indícios de vínculos com os princípios do desenvolvimento alternativo, ou seja, pautados nos princípios da autogestão, solidariedade, cooperação, igualdade de gênero e, sustentabilidade ambiental, demonstrando que foi posto em prática o ODS 11 que preconiza a relevância em nutrir as relações econômicas, sociais e ambientais positivas entre áreas urbana, periurbanas e rurais.

Como as frutas existentes no assentamento são produzidas em pequena escala, os assentados, de forma coletiva, compram algumas frutas, a exemplo da graviola e uva para complementar o processo agroindustrial. Após a fabricação das polpas, as mesmas são comercializadas pelo Programa Federal, conveniado à Prefeitura Municipal, denominado Compra Direta da Agricultura Familiar, sendo que, após pagas as despesas com o processo de produção, o saldo é dividido de maneira igualitária entre os assentados, participantes da produção. Assim, há o atendimento ao ODS 12 em sua meta de número 12.7 que aponta a necessidade de incentivar à prática de compras públicas e sustentáveis.

Através de relatos dos associados fica claro que, a criação e a continuidade do trabalho realizado junto a Agroindústria Fonte de Sabor resultaram na melhoria da qualidade de vida dos associados gerando inclusão social, através da geração de renda, além do fortalecimento do associativismo, valorização da mulher e do jovem rural. E, ainda faz parte da concretização dos trabalhos realizados, o agraciamento com os prêmios SEBRAE Mulher de Negócios na categoria Negócios Coletivos (Associação e Cooperativa) nas edições 2010, com $3^{\circ}$ lugar, 2011 com $2^{\circ}$ lugar e, 2012 com o $1^{\circ}$ lugar no Estado (ver Figura 2).

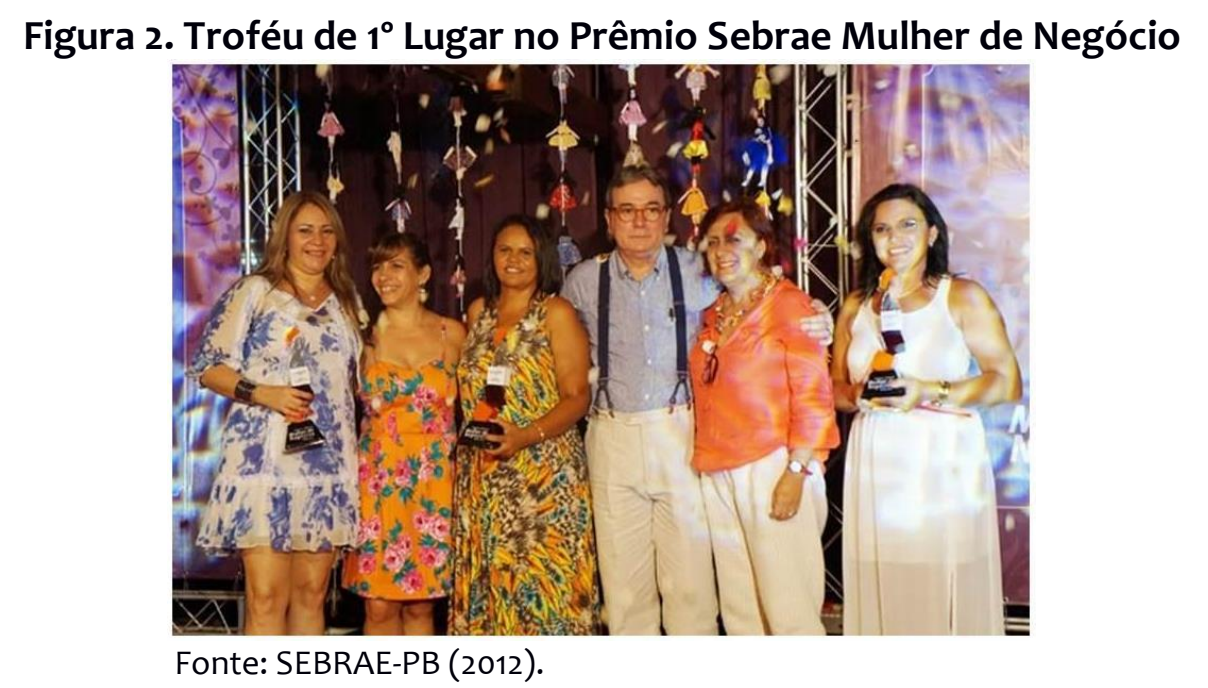

Ressalta-se que para alcançar os ODS's faz-se necessário a implementação de mecanismos proativos e eficientes visando superar os desafios territoriais, que também são globais. Ou seja, os desafios são pôr em prática a solidariedade, a igualdade e a proteção à natureza. Para tanto acredita-se que é preciso superar a fragmentação sistêmica de ações, assegurar a acessibilidade, garantir maior eficiência e eficácia, sensibilizar as pessoas para planejar e pôr em prática ações coletivas que transformem a vida dando dignidade, mas resguarde na mesma 
proporção a proteção à natureza e a emancipação social. Assim, os ODS's precisam ser complementados com indicadores que possam revelar estas nuances.

Deste modo, o sistema DASAF, atuando de maneira complementar estruturou suas dimensões, correlacionando com as variáveis, dentre elas a Organização Social. Esta variável, apontou níveis de relevância para ser acompanhada numa agroindústria familiar. No caso da Fonte de Sabor, viu-se que até o momento, o apoio dado por duas instituições (EMATER e a IACOC/PEASA/UFCG) e por um articulador social (CERSA) que fazem o acompanhamento das atividades realizadas nesta agroindústria, tem sido fundamental para as etapas de planejamento, de gestão e de continuidade do trabalho e da avaliação dos resultados obtidos.

Os atores sociais afirmaram que todos os temas apresentados eram importantes para as atividades e para os modos organizações internas e externas da Agroindústria, fato que proporcionou a inter-relação dos temas com as dimensões que são comuns tanto na estruturação dos princípios do desenvolvimento alternativo, quanto do desenvolvimento sustentável e, ainda com a economia solidária.

\section{Quadro 2. Sistema de Indicadores DASAF e a Ponderação da Importância da} Organização Social para a Agroindústria Fonte do Sabor

\begin{tabular}{|c|c|c|c|}
\hline Dimensão & Temas & Peso temas & Peso Dimensão \\
\hline \multirow{5}{*}{ Igualdade } & Estrutura do empreendimento & 0,1538 & \multirow{5}{*}{0,3240} \\
\hline & Trabalho & 0,1538 & \\
\hline & Organização social & 0,3077 & \\
\hline & Política Pública & 0,2692 & \\
\hline & Infraestrutura & 0,1154 & \\
\hline \multirow{4}{*}{ Solidariedade } & Estrutura do empreendimento & 0,3498 & \multirow{4}{*}{0,3015} \\
\hline & Trabalho & 0,1752 & \\
\hline & Organização social & 0,2753 & \\
\hline & Política Pública & 0,1997 & \\
\hline \multirow{5}{*}{$\begin{array}{l}\text { Proteção à } \\
\text { Natureza }\end{array}$} & Ambiente Natural & 0,1871 & \multirow{5}{*}{0,3745} \\
\hline & Organização social & 0,2606 & \\
\hline & Trabalho & 0,0976 & \\
\hline & Estrutura do empreendimento & 0,2274 & \\
\hline & Infraestrutura & 0,2274 & \\
\hline \multicolumn{2}{|r|}{ Total } & 3,000 & 1,000 \\
\hline
\end{tabular}

Fonte: Autores, 2018.

Viu-se que quando vinculada ao princípio Igualdade o tema Organização Social ficou em $1^{\circ}$ lugar, o que expressa que todos que participaram das rodas de conversas compreenderam que se a Agroindústria Fonte de Sabor não contasse com uma organização social que possibilitasse a igualdade de todas e todos seriam praticamente inviáveis as conquistas. Aliado a avaliação dos resultados viu-se ainda que foi relevante contar com uma Estrutura de Empreendimento que oferece as mesmas oportunidades. E, o modo de execução do Trabalho baseia-se no treinamento de todas as pessoas para executar todas as funções, bem como, na distribuição de tarefas e responsabilidades distribuídas horizontalmente, por isso estes temas ocuparam o $2^{\circ}$ e o $3^{\circ}$ lugar em nível de relevância. 
No princípio Solidariedade o tema Estrutura do Empreendimento ficou em destaque como o tema mais relevante e, a Organização Social ficou em $2^{\circ}$ lugar. Isto se dá pela compreensão de que é na Estrutura do Empreendimento que este princípio está mais forte para superar os conflitos na hora da produção, para compreender que uma pessoa vai se destacar em uma função enquanto outra vai precisar de ajuda para desempenhar a mesma função se houver a necessidade de substituição temporária e, assim a ajuda mútua e a mediação de conflitos necessitarão ser ultrapassados através do fortalecimento do princípio da solidariedade para que a organização social funcione adequadamente.

No princípio Proteção à Natureza, o tema Organização Social sobressaiu, a partir da compreensão de que as pessoas que estão na organização social do empreendimento e, por conseguinte no processo da tomada de decisão têm papéis fundamentais tanto na adoção de práticas sustentáveis e/ou ações corretivas para minimizar os impactos ambientais, quanto em promover ações de sensibilização e conscientização no tocante à relevância de ser um sujeito ecológico que respeita os limites da natureza e, que contribui de modo direto para que a vida possa existir e, que o trabalho realizado na Agroindústria possa seguir alinhado com a dinâmica de funcionamento da natureza.

Constatou-se que dentre as três dimensões do Sistema de Indicadores DASAF "Proteção à Natureza" é o que tem maior peso, ou seja, é a mais importante para que o trabalho e a produção na Agroindústria Fonte do Sabor continuem galgando sucesso, haja vista a ligação direta dos produtos beneficiados com necessidade de ter um ambiente natural equilibrado. No entanto as orientações e acompanhamento às práticas ambientalmente sustentáveis ainda carecem de mais detalhamento e processo de sensibilização dentre os membros da Associação do Assentamento São João II, ou seja, precisam romper os muros da Agroindústria Fonte de Sabor.

Estes foram os elementos que possibilitam elaborar algumas considerações sobre o modo de organização da agroindústria familiar que iniciou sua estruturação a partir da política territorial e, que tem fortes traços com o desenvolvimento alternativo e com o que preconiza a Agenda 2030 no tocante aos Objetivos do Desenvolvimento Sustentável, às Metas e, aos Meios de Implementação.

\section{Considerações Finais}

As constatações apontam que as agroindústrias familiares quando dispõem de apoio e acompanhamento conseguem se organizar ao ponto de demonstrar sua capacidade de difundir os princípios do desenvolvimento territorial, alternativo e sustentável. Assim, faz-se necessário que as agricultoras e agricultores tenham consciência de que os produtos gerados são mais do que simples mercadorias que carecem ser precificados. Eles oferecem para toda a população valores socioculturais ligados a preservação da natureza, a qualidade de vida das pessoas, ao equilíbrio da ingestão de alimento para a geração das condições de saúde humana e ambiental. Logo, o papel desempenhado por este tipo de empreendimento é fundamental para o alcance dos ODS's num curto lapso temporal que ainda resta, de aproximadamente 11 anos.

Por outro lado, a dinâmica territorial é compreendida como algo fundamental para combater as desigualdades, intensificando o processo de articulação entre 
agricultores e outros atores sociais. No caso concreto da agroindústria Fonte do Sabor este fato motivou a organização do grupo de mulheres tendo como elemento primordial formas de organização das ações a partir da contribuição das instituições. Com isto, foram impulsionados os ODS's dentre os quais destacou-se o número 17, cujo objetivo é Fortalecer os meios de implementação e revitalizar a parceria para o desenvolvimento sustentável.

Neste caso específico, evidenciou-se que as metas 17.8 e 17.14 que descrevem respectivamente a operacionalização do Banco de Tecnologia e o mecanismo de capacitação em ciência, tecnologia e inovação para os países menos desenvolvidos, aumentando o uso de tecnologias de capacitação, em particular das tecnologias de informação e comunicação; e, aumentar a coerência das políticas para o desenvolvimento sustentável foram plenamente atendidas.

E para corroborar ainda mais com as constatações mencionadas verificou-se que o Sistema de Indicadores DASAF conseguiu auxiliar na mensuração dos níveis de importância dos temas vinculados às atividades e ao modo de organização interna e externa da Agroindústria, fato que proporcionou a inter-relação dos temas com as dimensões que são comuns tanto na estruturação dos princípios do desenvolvimento alternativo, do desenvolvimento sustentável e da economia solidária, destacando que ainda há a necessidade de elaborar ações diretas para melhorar a relação das pessoas do Assentamento São João II com o princípio Proteção à Natureza.

Pari passu, ficou perceptível que as pessoas envolvidas no processo de trabalho conseguiram apresentar uma forma de organização baseada em iniciativas coletivas, a partir da organização da propriedade, do trabalho e da gestão solidária que tentam contrariar, por um lado, a separação entre capital e trabalho e, por outro, deixa de lado as trocas de favores que possam existir por parte das ajudas estatais para alienar, tornando reféns do paternalismo político as pessoas envolvidas na atividade econômica. Não se percebeu a centralização da economia através dos meios de produção capitalista, nem também um regime econômico controlado pelo Estado. Assim, aponta-se uma vinculação com o desenvolvimento alternativo.

Dentre a coluna de sustentação do desenvolvimento alternativo, verificou-se que existe uma inclusão da atividade, mas ainda podem ser melhorados os incentivos rumo a implantação dos valores de igualdade e de cidadania. Já que se verificou que os atores sociais têm iniciativas e poder de decisão. No entanto, na escala local é preciso ainda que haja uma ampliação da produção e comercialização dos produtos da agroindústria, incluindo uma maior divulgação e, também, a aquisição de selos para possibilitar a comercialização nos estabelecimentos do núcleo urbano e região.

Notou-se ainda que a forma de produção se baseou em iniciativas coletivas na agroindústria Fonte de Sabor. E, que o comando do estabelecimento demonstrou autonomia e capacidade de autogestão a partir do consenso dos membros vinculados a Associação de Produtores Rurais do Assentamento São João II.

Percebeu-se também que um elemento foi fundamental para que as forças de apoio dos grupos de assessoramentos atuassem e contribuíssem com 0 desenvolvimento da agroindústria e também de outras experiências homologadas, qual seja o alinhamento de ações e efetivação dos acessos aos programas dos governos Federal, Estadual e Municipal. Fato que na atualidade não está mais ocorrendo. 
Tem-se certeza de que ainda é preciso disseminar a relevância da agricultura familiar no território rural do Médio Piranhas, visando ultrapassar a lógica puramente capitalista baseada no tripé produção - riqueza - bem estar e, adotar a lógica pautada na terra - trabalho - emancipação social. Desse modo, o desenvolvimento ultrapassa suas características ligadas ao modelo dominante e se associaria ao modelo "alternativo" e sustentável, o qual baseia-se nas ações coletivas planejadas e concretizadas a partir da gestão solidária, da descentralização do poder e, da emancipação social, ressaltando então os princípios de igualdade, solidariedade e proteção à natureza.

Por fim, concluiu-se que as agroindústrias familiares e as políticas públicas que fortaleçam os territórios rurais são fundamentais, por um lado, para que os empreendimentos produtivos coletivos de agricultoras e agricultores familiares alcancem o desenvolvimento alternativo a partir do objetivo de redução da pobreza e da geração de renda, a ponto de mudar a realidade das pessoas e promover qualidade de vida em equilíbrio com a natureza; e, por outro lado, esses são elementos primordiais para consagrarmos os acordos firmados em escala mundial, promulgados a partir da Agenda 2030 e dos ODS's.

\section{REFERÊNCIAS}

CARVALHO, I. S. H. de; FRANCO, A. B. O papel do campesinato na construção da sociedade do decrescimento. IN: LENA, P.; NASCIMENTO, E. P. (Orgs). Enfrentando os limites do crescimento: sustentabilidade, decrescimento e prosperidade. Rio de Janeiro: Garamond, 2012.

CATTANI, A. D. (Org.). Autonomia-Emancipação Social. In: Dicionário de trabalho e tecnologia. Porto Alegre - RS: Editora da UFRGS, 2006.

ENGEBRETSEN, E; HEGGEN, K.; OTTERSEN, O. P. The Sustainable Development Goals: ambiguities of accountability. The Lancelot. Vol. 389, p. 365, January 28, 2017.

FAO - ORGANIZAÇÃO DAS NAÇÕES UNIDAS PARA A ALIMENTAÇÃO E AGRICULTURA. BOJANIC, A. J. Superação da fome e da pobreza no Brasil: iniciativas brasileiras. Brasília - DF: FAO, 2016.

FURTADO, C. Teoria e política do desenvolvimento econômico. $8^{\text {a }}$ ed. São Paulo: Editora Nacional, 1983.

. Em busca de novo modelo: reflexões sobre a crise contemporânea $2^{\mathrm{a}}$ ed. São Paulo: Paz e Terra, 2002.

HAESBAERT, R. Identidades territoriais. In: ROSENDAHL, Z.; CORRÊA, R. L.. Manifestações da cultura no espaço. Rio de Janeiro: EDUERJ, 1999.

LEFF, E. Discursos sustentáveis. São Paulo: Cortez, 2010. 
MELLO, J. Estratégias de superação da pobreza no Brasil e impactos no meio rural. Rio de Janeiro - RJ: IPEA, 2018.

OLIVEIRA, F. Elegia para uma Re(li)gião: SUDENE, Nordeste. Planejamento e conflito de classes. $3^{\text {a }}$ ed. Rio de Janeiro: Paz e Terra, 1981.

. Crítica à razão dualista - O Ornitorrinco. $3^{\mathrm{a}}$ Reimpressão. São Paulo - SP:

Editora Boitempo, 2011.

ORGANIZAÇÕES DAS NAÇÕES UNIDAS. PROGRAMA DAS NAÇÕES UNIDAS PARA O DESENVOLVIMENTO. Articulando os programas de governo com a Agenda 2030 para o desenvolvimento sustentável: orientações para organizações políticas e a cidadania. Brasília - DF: PNUD/ ONU BR, 2018.

PERAFÁN, M. E. V.; GRISA, C.; TARTARUGA, I. P.; RAMIREZ-MIRANDA, C. A. (Orgs.). Gestão e dinâmica em desenvolvimento territorial. Curitiba-PR: CRV, 2018.

RIELLA, A. (Org.) Globalización, desarrollo y territorios menos favorecidos. Montevideo - Uruguay: Imprenta Rosgal, 2006.

SALES, R. M. M. A agricultura familiar e os princípios do desenvolvimento alternativo e sustentável no espaço rural de Pombal/PB: uma proposição de sistema de indicadores. Campina Grande - PB: CTRN/UFCG, 2014. (Tese de Doutoramento).

SANTOS, B. S.; RODRÍGUEZ, C. Introdução: para ampliar o cânone da produção. In: SANTOS, B. S. (Org.) Produzir para viver: os caminhos da produção não capitalista. Rio de Janeiro: Civilização Brasileira, 2002.

SANTOS, F. FERNANDES, P. F.; ROCKETT, F. C.; OLIVEIRA, A. B. A. Avaliação da inserção de alimentos orgânicos provenientes da agricultura familiar na alimentação escolar, em municípios dos territórios rurais do Rio Grande do Sul, Brasil. Revista Ciências e Saúde Coletiva. Vol. 19, nº 5, maio, 2014.

SANTOS, M.; SILVEIRA, M. L. O Brasil: Território e sociedade no início do século XXI. $10^{\mathrm{a}}$ ed., São Paulo/ Rio de Janeiro: Record, 2010.

SCHNEIDER, S.; FERRARI, D. L. Cadeias curtas, cooperação e produtos de qualidade na agricultura familiar - o processo de relocalização da produção agroalimentar em Santa Catarina. Organizações Rurais \& Agroindustriais. Vol. 17, $\mathrm{n}^{\circ}$ 1, enero-marzo, p. 56-71. Lavras - MG: Universidade Federal de Lavras, 2015.

SOUZA, G. A. S. Projeto COOPERAR: levantamento histórico da política de combate à pobreza rural no Estado da Paraíba em parceria com o Banco Mundial. João Pessoa/PB: UFPB, 2015. (Monografia em nível de Graduação). 
YUNUS, M. Um mundo sem pobreza: a empresa social e o futuro do capitalismo. São Paulo: Ática, 2008.

Ricélia Maria Marinho Sales. Técnica em Saneamento em nível médio pelo Instituto Federal da Paraíba. Graduada em Geografia pela Universidade Federal da Paraíba. Mestre em Geografia pela Universidade Federal do Rio Grande do Norte. Doutora em Recursos Naturais pela Universidade Federal de Campina Grande. Professora Adjunta da Universidade Federal de Campina Grande do Centro de Ciências e Tecnologia Agroalimentar, na área de Ciências do Ambiente. riceliamms@gmail.com

Mônica Tejo Cavalcanti. Graduada em Farmácia pela Universidade Federal da Paraíba. Mestre em Ciência e Tecnologia de Alimentos pela Universidade Federal da Paraíba. Doutora em Engenharia de Processos pela Universidade Federal de Campina Grande. Professora Adjunto IV da Universidade Federal de Campina Grande.monicatejoc@yahoo.com.br

Karla Jarlita de Moura Silva. Graduanda em Engenharia Ambiental na Universidade Federal de Campina Grande. karla_jarlita@hotmail.com

Patrícia de Jesus Silva. Graduanda em Engenharia Ambiental na Universidade Federal de Campina Grande. pjsilva0210@gmail.com

Como citar: SALES, Ricélia Maria Marinho et al. Agroindústria Familiar, ODS's e Desenvolvimento Alternativo: um estudo sobre a Fonte do Sabor do Semiárido Paraibano/Brasil. Redes, Santa Cruz do Sul, v. 24, n. 3, p. 142-162, set. 2019. ISSN 1982-6745. Disponível em: https://doi.org/10.17058/redes.v24i3.14122. 